\title{
The Technology Acceptance Model (TAM) and its Application to the Utilization of Mobile Learning Technologies
}

\author{
David Gitumu Mugo ${ }^{1 *}$, Kageni Njagi ${ }^{2}$, Bernard Chemwei ${ }^{2}$ \\ and Jared Ochwagi Motanya ${ }^{1}$ \\ ${ }^{1}$ Karatina University, P.O.Box 1957-10101, Karatina, Kenya. \\ ${ }^{2}$ Kabarak University, P.O.Private Bag-20157 Kabarak, Kenya.
}

\begin{abstract}
Authors' contributions
This work was carried out in collaboration between all authors. Author DGM designed the study contacted literature and wrote the first draft. Authors $K N$ and BC proofread the manuscript and provided insights that ensured the theme was clearly articulated. Author JOM did the editing and ensured the manuscripts met grammatical and regulations set out by the journal. All authors read and approved the final manuscript.
\end{abstract}

Article Information

DOI: $10.9734 / \mathrm{BJMCS} / 2017 / 29015$

Editor(s):

(1) Fangfei Li, Department of Mathematics, East China University of Science and Technology, Shanghai, China. (2) Tian-Xiao He, Department of Mathematics and Computer Science, Illinois Wesleyan University, USA. Reviewers:

(1) John Vianne B. Murcia, University of Mindanao, Philippines. (2) Jama Raiyn Al-Qasemi, Academic College of Education, Baqa Al Qarbiah, Israel. (3) A. Balavivekanandhan, Anna University, India. (4) Nafsaniath Fathema, University of Wisconsin Madison, USA. Complete Peer review History: http://www.sciencedomain.org/review-history/17750

Mini-review Article

Received: $17^{\text {th }}$ August 2016

Accepted: $19^{\text {th }}$ December 2016

Published: $8^{\text {th }}$ February 2017

\begin{abstract}
Researchers have argued that inclusion of technologies in the teaching-learning places must be preceded by the user accepting the technology. Without this effort, the technologies remain abandoned or heavily underutilized once supplied to school system. So researchers have proposed frameworks that can inform policy makers, education managers and teachers on how best technology can be incorporated in an educational scenario. The most popular of all frameworks is the Technology Acceptance Model (TAM) as proposed by Davis, 1989. This study describes how the TAM has been used in predicting the acceptance and utilization of various technologies in teaching and learning places. The study then arguments how TAM can be adopted in the development and utilization of the most recent technological innovation for teaching and learning: - mobile technologies. The study was a documentary analysis of virtual documents stored electronically for access through the internet, text books, archival repositories as well as encyclopedia and was able to reveal that despite attitudinal and technical challenges, mobile technologies are receiving acceptance as useful resources for all pedagogical practices.
\end{abstract}

*Corresponding author: E-mail:dmugo@karu.ac.ke,davidgm@karatinauniversity.ac.ke; 
Keywords: Instruction; technology; technology acceptance model; mobile technologies.

\section{Introduction}

In many countries of the world, governments are changing their national curriculum with a view of adding more of information communication technology into it. The investment is directed towards policy, teacher training, and technology adoption. The policies, training and technology adoption programs are directed towards efforts that promote the acceptance of the technology.

Attempts to include technologies in the education market place have been with educationist for quite some time. Literature indicates that the electronic industry has always exerted pressure on the education system to accept and utilize technologies not only in teaching and learning, but in the support of other services within the school system [1]. However, a great challenge to the inclusion of technology in education is predicting its acceptance and eventually its utilizations, especially for academic purpose. Bowen in Davis [2] observes that sufficient utilization of any educational technology in the education place is often obstructed by the unwillingness of the user (teachers and students) to accept and adopt that technology.

The unwillingness to accept and adopt technology can be referred as resistance to technology. Resistance to technology has been persistent in the education place for quite some time. Makau [1] the education systems resisted biro pens, slide rules, electronic calculators as well as computers. The e-learning concept experienced an equal measure of resistance despite efforts to popularize it [3]. Park [4] observes that achieving success in programs that propose to include technologies in education is often quite challenging. Consequently innovators and designers of electronic products (such as IBM and Xerox) have often preferred to measure user perceptions before introducing any technology anywhere, including the school place. According to Davis [2] such measures are helpful in informing industry to design, build and implement products that respond to user reactions, tastes and preferences. This point of view is also held by Park [4] who arguments that measuring user perceptions is important in gauging how the user perceive and react to the elements of any technology. The outcomes of the measurements are equally useful to administrators and managers, who use such results to create mechanisms for attracting more users to adopt the technology. So for a long time now, industry players have been relying on instruments, which have received acceptance and validation by researchers in the training and electronic industry. The instruments are supported on theoretical structures referred to as technology acceptance frameworks.

\section{Technology Acceptance Frameworks}

The determinants of technology acceptance and utilization have been widely interrogated in literature. Shroff et al. [5-6], discusses the various frameworks used to measure the determinants of technology acceptance and utilization. Among the frameworks include the Diffusion of Innovation Model by Rogers, Technology Acceptance Model (TAM) by Davis and the Theory of Reasoned Action (TRA) by Aizen and Eishbein. Saga and Zmud in Kurnia et al. [6] suggest that amongst other models, the Technology Acceptance Model (TAM) has been the most influential and widely adopted to predict the acceptance and use of various technologies for learning. This is because the model has a strong theoretical basis and enjoys sufficient empirical support. When used effectively, the model can save an educational institution the risk of investing in a technology that may remain abandoned or grossly underutilized.

\section{The Technology Acceptance Model (TAM)}

In this section, we will explore the technology acceptance model as proposed by Davis. Originally proposed Fred Davis in 1985 as a doctoral thesis at the Massachusetts Institute of Technology, current literature indicates that TAM is a highly cited model. Chuttur [7] argues that the wide acceptance of TAM is based on the fact that the model has a sound theoretical assumption and practical effectiveness. From the time is was proposed in 1985, the model has been refined so as to incorporate variables and relationships obtained from 
the Fishbein and Ajzen theory of reasoned action (TRA) of 1975. The output from the adjustments was a more refined model essential for anyone willing to interrogate the theory around technology acceptance and its utilization in learning.

The model has been designed to show how users come to accept and use a technology. The theoretical basis is built on the premise that when users are presented with a new technology, three major factors influence their decision on how and when they will use it. The first determinant is its perceived usefulness (PU), the second is the perceived ease of use (PEOU), while the third determinant is user attitude towards usage (ATU). According to Davis [2,5] perceived usefulness (PU) is the degree to which a user believes that using a particular system would enhance his or her job performance.

On the other hand, perceived ease-of-use (PEOU) is the degree to which a user believes that using a particular technology would be free from effort. In other words it is the degree to which consumers perceive a technology as better than its substitutes, [8]. Commenting on the model, Chen et al. [9,4] extends the argument that perceived usefulness (PU) and perceived ease of use (PEOU) positively affects the attitudes toward usage (ATU) of a technology. The relationship between these determinants can be illustrated by the model in Fig. 1 as suggested by Davis.

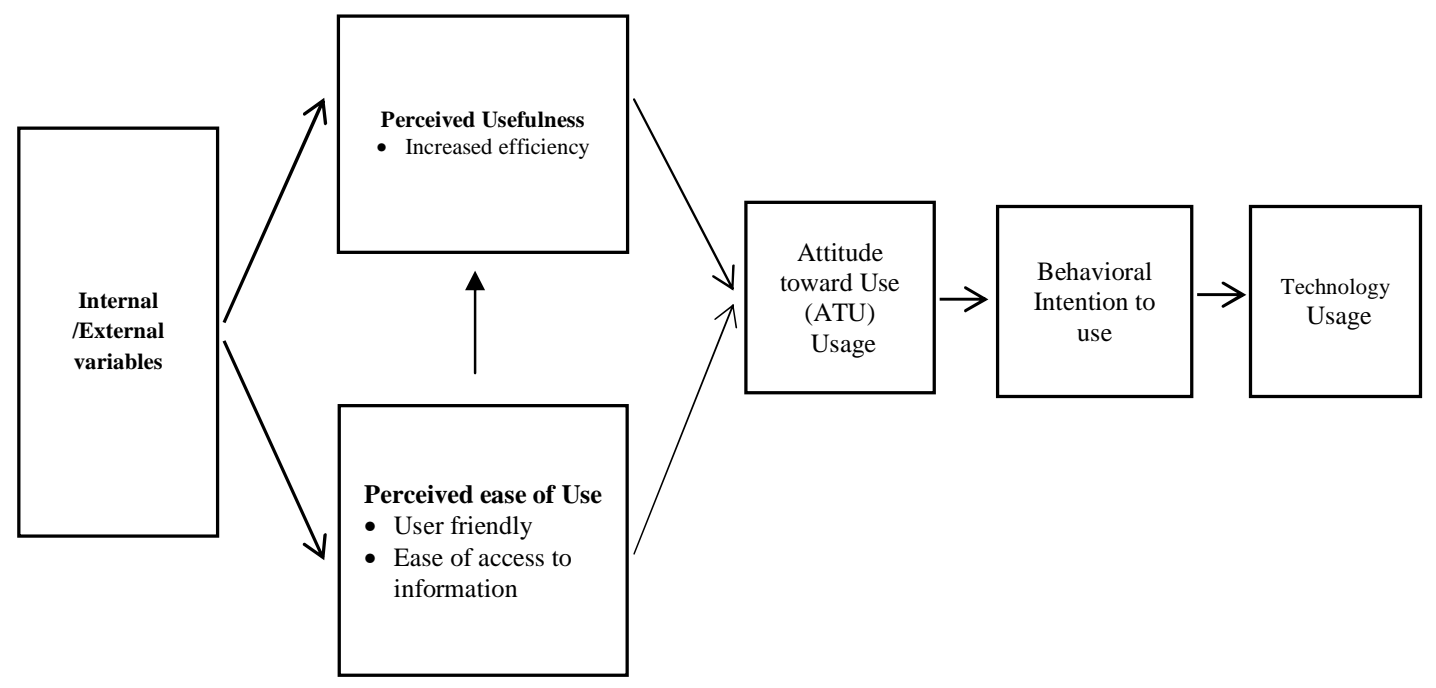

Fig. 1. The technology acceptance model [2]

In addition, both perceived ease of use and perceived usefulness are influenced by some critical variables. Different scholars have given their suggestions on the variables that determine the usefulness and ease of use of a technology. While investigating the implementation of Learning Management Systems at the university of Saudi Arabia, Asiri, Mohamud, Abu-Bakar and Ayub in Alharbi and steve [10] proposed two categories of such variables:- internal variables and external variables. Internal variables consist of factors such as the attitude of the user, their pedagogical beliefs towards, and level of competency. The authors confirmed that a positive attitude towards technology will likely motivate a user to utilize the technology. Further, along similar lines with other studies, beliefs about e-learning were found to be important in determining the use of a technology. The study noted that the use of technology could be predicted by competency level, meaning that having the skills and knowledge to use a system will affect its utilization. On the other hand, external variables include those external barriers faced by users during utilization. Such factors include organizational barriers, technological barriers, and social barriers. Similarly, demographical factors such as gender, computer self-efficacy, and levels of training (competency) are also used to predict technological usage. 


\section{Practical Application of TAM}

The Technology Acceptance Model has been applied in various information technology and information system areas [9]. Researchers have identified specific areas where the model has been adopted. Moon and Kin [11] used the model to explain the users' acceptance of World-Wide-Web in an educational context; Lin et al. [12] in Chen and Chen et al. used the model in clarifying e-stock users' behavioral intention, Chen and Chen et al. [9] adopted the model while investigating automotive telematics users' intention while Stern et al. [13] used the model in their studies on consumers' acceptance of online auctions. Other researchers, Serenko et al. [14] used the model to assess user acceptance of interface agents in daily work applications whereas Muller-Seitz et al. [15] used the same model to determine customer acceptance of Radio Frequency Identification (RFID). Almasri [16] arguments that TAM is an acceptable model and has been employed in many information technology and information system areas such as e-learning, World-Wide-Web, online auctions, Radio Frequency Identification (RFID), e-portfolio systems, wireless LAN, E-government, Ecommerce, internet banking, and mobile learning. In this regard therefore, TAM is a model that can inform technology designers on the impact of the system to the user's behavior. Alharbi and Steve [10] supports that TAM has been adopted and tested as a useful framework in the field of information science and Learning Management Systems. Many others scholars such as Seyal et al. [17,18,2] also attests that TAM is a sufficiently influential research model, whose tools have provided statistically reliable results.

\section{Application of TAM in Learning with Mobile Devices}

In recent years, individuals and institutions have fully accepted that Information Communication Technologies (ICT) can enable them to perform their functions in a much improved way [19]. However, owing to the affordance and conveniences provided by mobile technologies, consumers are shifting their preferences from fixed technologies towards technologies that are mobile. This has resulted to ready acceptance and adoption of the mobile technologies across the various sectors of human endeavors, including education [20].

Consequently, the use of mobile technologies for educational purposes is becoming a common practice and expectation amongst leaners. Rueckert et al. [21] arguments that learners (particularly those in rural and remote areas) are demonstrating eagerness to use mobile technologies as tools that can extend beyond communication and entertainment. The argument is that the devices being portable, are perceived convenient, affording learners the freedom to study when they want. Besides, mobile devices are argued to afford student ownership of the learning process which can produce positive learning experiences. Based on these affordances, scholars have assumed that the technologies cannot be wished away.

In light of these developments, researchers in the area of educational technology are interested in determining if m-learning would fit into an existing technology adoption theory. Since TAM has been adopted in numerous fields of communication technology, recent research activities in the area of education technology have endeavored to establish if TAM can also apply within a Mobile learning context. In this regard, literature is awash with studies that endeavor to fit mobile technologies into the Technology Acceptance Model. In doing so, researchers have discussed the technologies under the following considerations: perceived usefulness, perceived ease of use, and attitude towards utilization.

\subsection{Perceived usefulness}

Perceived usefulness of a mobile device is associated with its ability to provide a teacher with ease of access to online study groups, and to the learner instant access to numerous academic websites, graphics, video simulations and academic films. Graphics, video simulations and academic films are used by instructors to demonstrate processes and events within the curriculum. The devices are avenues that provide opportunity for accessing learning content any time anywhere, often times providing chances for individualized learning. Valk et al. [22] suggest that the benefits of mobile devices are not merely limited to increased access to 
educational services, but can also facilitate changes in the character of learning modalities that in turn has positive impacts on educational outcomes. Mobile devices are useful to lecturers and students as they allow them to utilize "dead time" effectively. So when travelling, waiting for a meeting to start, when waiting for a bus or when waiting for a lecture, mobile devices can provide opportunity for meaningful engagement with learning content. Geddes in Valk et al. [22] observes that m-Learning can maintain the appeal of learning and provides a motivating factor that can at times be lacking in traditional modes of education. It is also true that most mobile devices are relatively cheaper to buy than their computing counterparts, and run on smaller amounts of power than desktop and laptop computers. They are therefore accessible to lower end market segment, and particularly useful to people with limited access to mains electricity. Mobile devices, particularly those running on Android Operating System have useful apps such as cameras, video player, email, calculator, notebook, sound recorder, organizers and dictionaries which students and teachers can find useful in performing tasks specific to curricular engagements. Besides, they can find them even more useful for downloading appropriate apps generated by education industry players and by independent but licensed software developers.

\subsection{Perceived ease of use}

The second aspect is perceived ease of use (PEOU). The argument is that, mobile devices have an easy to use operating system which manages its hardware and software. Examples of popular operating systems on mobile devices are Android, Symbian iOS and Windows phone. The operating systems are designed as user friendly systems whose operation is experiential. The user does not require formal training for them to operate the interface. Within thirty (30) or so minutes of operation, a user can navigate through the graphical user interphase with ease. On the same vein, mobile devices are designed to have at least one home screen. The home screen displays the main menu, apps and widgets. The user can customize the home screen, or add an extra home screen, providing them with freedom of arranging the apps on an appropriate page. Besides the user can select and downloads apps that are unique to their needs, tastes and preferences. Thirdly todays' mobile devices have a large internal memory (up to $16 \mathrm{~GB}$ ) and slots for a large capacity microSD cards. This makes it convenient and easy for users to save and retrieve files downloaded from the net or obtained from any other computing devices. Lastly many mobile devices are portable, have inbuilt net interface that allow Internet connectivity, either through Wi-Fi, blue tooth, hotspot, GPRS/EDGE/3G or 4G facilities. This gives the user support, ease and freedom to carry and connect to the net as well as share or receive academic data and files without the need of plugging extra hardware.

\subsection{Attitude towards use}

The third aspect is related to attitude towards use (ATU). As earlier indicated, the attitude of a user towards usage of a technology is an important element in determining the acceptance of the technology. A mistake made by donor agencies is to take a technology to schools then expect teachers and learners to utilize. Such users get excessive exposure and are subjected to anxiety towards it especially when the technology is not easy to use. In this regard, Rueckert et al. [21] observe that users walk away in frustration, and a negative attitude is projected towards the technology. So a good mobile learning environment must be created (preferably by training users). By so doing, users are able to change their perception towards the technology, making them embrace its utilization.

Abu-Al-Aish and Steve [23] were able to investigate attitudinal issues that influence the adoption of mobile technologies in teaching and learning. In their study titled "Factors Influencing Students' Acceptance of MLearning: An Investigation in Higher Education", the authors makes reference to the works of Park [3] to argument that the general attitude amongst educators is that mobile technologies have the potential to disturb the learning process. Based on this attitude, many school systems across the globe do not accept the use of mobile devices within the school system owing to their potential to "disturb" learning. In many countries of the world (Kenya included), the technologies are associated with abetting dishonesty and exam irregularities. The second attitudinal issues revolve around the logistics of implementing the technology. Abu-Al-Aish, Ahmad, and Steve [23] focus on the lecturer's unwillingness to accept and utilize the technology because 
“...they might face difficulties in trying to use it effectively as the technology may require a lot of effort to implement". Thirdly, the technological limitations of the technology itself raises attitudinal issues further. Stockwells in Rueckert et al. [21] in their study on the perception and experiences of mobile learning, indicated that the usability and willingness of teaching staff and students to use mobile for learning activities was more attitudinal, and was not necessarily by to their willingness or unwillingness to use the devices, but more so its dependent on the inherent technical limitations that the devices portends - a small screen and a limiting keyboard. In their recommendations, the authors stated that if innovators resolved these limitation(s) (e.g. let's say by designing a larger but wireless keyboard) mobile technologies would be a viable and exciting option that would create meaningful learning experiences.

\section{Conclusion}

From this discussion we have obtained an appropriate opinion that Mobile technologies are gradually getting a place in pedagogy and in the educational system. Research findings support the argument that the technologies are not only useful, but also easy to use. However, there exists challenges in attitude, and educators must work hard to address attitudinal issues arising from learner, staff, management and policy makers. Therefore, before mobile technologies can be adopted in any learning environment there is need to conduct scientific investigation, guided by an appropriate technology acceptance model (preferably TAM) with a view of identifying the factors that may hinder sustained acceptance of the technologies into the education system(s). This argument is in line with the investigations by Chen et al. [9] who collaborates that determinants of student perceptions of m-learning need to be investigated as an initial step of implementing m-learning at whatever level of education. In the Kenyan education system, specifically at university level, these determinants are currently under investigation.

\section{Competing Interests}

Authors have declared that no competing interests exist.

\section{References}

[1] Makau BM. Computer in Kenyan Schools; a case study of an innovation in Kenya. Canada: IDRC; 1988.

[2] Davis Fred D. Perceived usefulness, perceived ease of use, and user acceptance of information technology. MIS Quarterly. 1989;319-340.

[3] Mugo DG. Integrating emerging ICT in instruction of science. Success and challenges facing e-school projects in Kenya. Kenyatta University, Unpublished M. Ed thesis.

[4] Park Sung Youl. An analysis of the technology acceptance model in understanding university students. Behavioral Intention to Use e-Learning. Educational Technology \& Society. 2009;12(3): 150-162.

[5] Shroff Ronnie Homi, Christopher Charles Deen, Mee Wah Eugenia NG. Analysis of the technology acceptance model in examining students behavioural intention to use an e-portfolio system; 2011.

[6] Kurnia S, Smith S, Lee H. Consumers perception of mobile internet in Australia, Department of information systems; 2005.

[7] Chuttur Mohammad Y. Overview of the technology acceptance model: Origins, developments and future directions. Working Papers on Information Systems. 2009;9(37):9-37. 
[8] Jahangir Nadim, Noorjahan Begum. The role of perceived usefulness, perceived ease of use, security and privacy, and customer attitude to engender customer adaptation in the context of electronic banking. African Journal of Business Management. 2008;2(2):32.

[9] Chen Shih-Chih, Li Shing-Han, Li Chien-Yi. Recent related research in technology acceptance model: A literature review. Australian Journal of Business and Management Research. 2011;1(9): 124.

[10] Alharbi Saleh, Steve Drew. Using the technology acceptance model in understanding academics behavioural intention to use learning management systems. International Journal of Advanced Computer Science and Applications (IJACSA). 2014;5(1).

[11] Ji-Won Moon, Young-Gul Kim. Extending the TAM for a world-wide-web context. Information \& Management. 2001;38:228

[12] Lin Chien-Hsin, Hsin-Yu Shih, Peter Sher J. Integrating technology readiness into technology acceptance: The TRAM model. Psychology \& Marketing. 2007;24(7):641-657.

[13] Stern Barbara B, Marla Royne B, Thomas Stafford F, Carol Bienstock C. Consumer acceptance of online auctions: An extension and revision of the TAM. Psychology \& Marketing. 2008;25(7):619636.

[14] Serenko Alexander, Nick Bontis, Brian Detlor. End-user adoption of animated interface agentsin everyday work applications. Behaviour \& Information Technology. 2007;26(2):119-132.

[15] Müller-Seitz, Gordon Kirsti Dautzenberg, Utho Creusen, Christine Stromereder. Customer acceptance of RFID technology: Evidence from the German electronic retail sector. Journal of Retailing and Consumer Services. 2009;16(1):31-39.

[16] Almasri Ammar Khader Mohammad. The influence on mobile learning based on Technology Acceptance Model (TAM), Mobile Readiness (MR) and Perceived Interaction (PI) for higher education students; 2014.

[17] Seyal Afzaal H, Abd Rahman Noah, Rudy Ramlie, Armanadurni Abdul Rahman. A preliminary study of students attitude on m-Learning: An application of technology acceptance model. International Journal of Information and Education Technology. 2015;5(8).

[18] Huang Jen-Hung, Yu-Ru Lin, Shu-Ting Chuang. Elucidating user behavior of mobile learning: A perspective of the extended technology acceptance model. The Electronic Library. 2007;25(5):585598.

[19] Kandiri John Mugo. Effective implementation of technology innovations in higher education institutions: A survey of selected projects in universities in Africa. PhD diss., Kenyatta University; 2014.

[20] Mberia PM, Ofafa GA, Muathe MA, Muli J. An empirical investigation on the relationship between technological infrastructure and government regulations on Effective operations of m-payment systems in Kenya. International Journal of Arts and Commerce; 2013.

[21] Rueckert Daniel, Dong-Joong Kim, Daeryong Seo. Students' perceptions and experiences of mobile Learning. Announcements \& Call for Papers. 2013;52. 
[22] Valk John-Harmen, Ahmed Rashid T, Laurent Elder. Using mobile phones to improve educational outcomes: An analysis of evidence from Asia. The International Review of Research in Open and Distributed Learning. 2010;11(1):117-140.

[23] Abu-Al-Aish Ahmad, Steve Love. Factors influencing students' acceptance of m-learning: An investigation in higher education. The International Review of Research in Open and Distributed Learning. 2013;14(5).

(C) 2017 Mugo et al.; This is an Open Access article distributed under the terms of the Creative Commons Attribution License (http://creativecommons.org/licenses/by/4.0), which permits unrestricted use, distribution, and reproduction in any medium, provided the original work is properly cited.

Peer-review history:

The peer review history for this paper can be accessed here (Please copy paste the total link in your browser address bar)

http://sciencedomain.org/review-history/17750 